\title{
Oxytocin Release is Strongly Associated With Premature Infant Behavioral Patterns
}

\author{
Vittner $\mathrm{D}^{1,2}$, Lawhon $\mathrm{g}^{3}$, D'Agata $\mathrm{A}^{3,4}$, McGrath $\mathrm{JM}^{6}$, Young $\mathrm{E}^{1,4-5}$ \\ University of Connecticut, School of Nursing, Storrs, CT \\ ${ }^{2}$ WakeMed Health \& Hospitals, Raleigh, NC \\ ${ }^{3}$ Abington Hospital-Jefferson Health System Abington, PA \\ ${ }^{4}$ University of Rhode Island, Kingston, RI \\ ${ }^{5}$ Genetics and Genome Sciences, UCONN School of Medicine, Farmington, CT \\ ${ }^{6}$ Institute for Systems Genomics, University of Connecticut, Storrs, CT,
}

\section{Background/Significance}

There is growing evidence that the premature infant and the developing brain, is influenced especially in the vulnerable window of time the infant is cared for in the Newborn Intensive Care Unit (NICU). It has been optimistically, yet incorrectly, proposed that healthy preterm infants without major complications eventually catch-up developmentally to term infants. Research suggests as preterm infants mature, many remain increasingly disadvantaged on many neurodevelopmental outcomes. Parental touch, especially during skin-to-skin contact (SSC) has the potential to reduce the adverse consequences of prematurity. SSC is an evidenced-based holding strategy that increases parental proximity and provides a continuous interactive environment known to enhance infant physiologic stability and affective closeness between parents and their infants.

\section{Purpose}

The purpose of this research study was to examine bio-behavioral mechanisms; and specifically, to evaluate whether infants with higher oxytocin levels have more competent neurobehavioral functioning.

\section{Methods}

This randomized cross-over design study used a three-day timeframe conducted in the NICU. The sample consists of 28 stable preterm infants (30 0/7 - 34 6/7 weeks gestational age between 3 -10 days old) and their mothers/fathers. After informed consent, each triad was randomly assigned to one of two sequences: maternal SSC on day one and paternal SSC on day two; or paternal SSC on day one and maternal SSC on day two. Infants' and parents' saliva samples for oxytocin and cortisol were collected pre-SSC, 60-min during-SSC, and 45-min post-SSC. Infant neurobehavioral assessment using the NICU Neurobehavioral Network Scale (NNNS) was collected prior to hospital discharge.

\section{Analysis/Results}

Data were analyzed using IBM SPSS version 25; descriptive statistics were used to describe demographic characteristic variables. Paired t-tests were used to examine infant salivary oxytocin levels and infant neurobehavioral functioning. Oxytocin release was activated for mothers $(\mathrm{p}<0.001)$, fathers $(\mathrm{p}<0.002)$ and infants $(\mathrm{p}<0.002)$ during skin-to-skin contact. There was also a relationship identified using Pearson's
DOI: $10.14434 /$ do.v13i1.29087 correlation between infant oxytocin levels and the infant's neurobehavioral functioning. Infant salivary cortisol levels were correlated to summary scales of infant stress behaviors and higher levels of disorganization. Infants held SSC with their mother with higher salivary oxytocin levels had significant correlations to high self-regulatory summary scores $(\mathrm{r}=.544, \mathrm{p}<0.003)$, and a strong negative correlation to excitability summary scores ( $\mathrm{r}=-$ $.761, \mathrm{p}<0.001)$. These infants with lower salivary cortisol levels had a strong negative correlation to handling summary scores $(\mathrm{r}=.594, \mathrm{p}<0.025)$ and stress summary scores $(\mathrm{r}=-.534, \mathrm{p}<.049)$. Infants salivary oxytocin levels, when held SSC by their fathers, had strong correlations with higher self regulatory summary scores $(\mathrm{r}=.396, \mathrm{p}<0.041)$, and a moderate negative correlation with infant lethargy summary scores $(\mathrm{r}=-.400, \mathrm{p}<0.039)$. There was also a moderate correlation for infants held SSC by their fathers with higher cortisol levels to have higher lethargy summary scores $(r=.459, \mathrm{p}<0.016)$.

\section{Conclusions}

Despite advances in the NICU, premature infants remain at risk for adverse neurodevelopmental outcomes. This is an important step in exploring oxytocin as a potential moderator to improve infant neurodevelopmental outcomes and the effects of SSC on mothers, fathers and infants. Nurses can use SSC as a strategy to activate oxytocin and enhance infant developmental outcomes. This study also supports, in conjunction with the views of the American Academy of Pediatrics, the value that all preterm infants and their parents should have the opportunity for SSC every day.

\section{Keywords}

Skin-to-skin contact; preterm infant; oxytocin; neurodevelopment; NICU Network Neurobehavioral Scale Statement of Financial Support:

The authors have no financial relationships with commercial entities to disclose.

\section{Acknowledgements}

This study was supported with funding from the National Association of Neonatal Nurses, American Nurses Foundation (Eastern Nursing Research Society), Sigma Theta Tau International (Mu Chapter) and the University of Connecticut, School of Nursing (Toner funds). 
References

1. Baley, J. (2015). Skin-to-skin care for term and preterm infants in the neonatal ICU. Pediatrics, 136(3), 596-599.

2. Conde-Agudelo, A., Belizan, J. M., \& Rosello-Diaz, J. (2014). Kangaroo mother care to reduce morbidity and mortality in low birth weight infants. Cochrane Database of Systematic Review, 4(4), CD002771.

3. Cong, X., Ludington-Hoe, S. M., Hussain, N., Cusson, R. M., Walsh, S., Vazquez, V., ... Vittner, D. (2015). Parental oxytocin responses during skin to skin contact with preterm infants. Early Human Development, 91, 401-406.

4. Feldman, R. (2015). Sensitive periods in human social development: New insights from research on oxytocin, synchrony and high-risk parenting. Development and Psychopathology, 27, 369-395. http://dx.doi.org/10.1017/S0954579415000048

5. Feldman, R., \& Eidelman, A. (2003). Mother-infant skin to skin contact (kangaroo care) accelerates autonomic and neurobehavioral maturation in preterm infants. Developmental Medicine and Child Neurology, 45, 274-281.

6. Ferber, S. G., \& Makhoul, I. R. (2004). The effects of skin to skin contact (kangaroo care) shortly after birth on the neurobehavioral responses of the term newborn: A randomized controlled trial. Pediatrics, 113(4), 858-865.

7. Hack, M., Taylor, H., Schluchter, M., Andreias, L., Drotar, D., \& Klein, N. (2009). Behavioral outcomes of extremely low birthweight children at age 8 years. Journal of Developmental Behavioral Pediatrics, 30(2), 122-130.

8. Howson, C. P., Kinney, M. V., \& Lawn, J. E. (2012). Born to Soon: The global action report on preterm birth. March of Dimes, PMNCH, Save the Children, WHO.
9. Lee, H. J., Macbeth, A. H., Pagani, J. H., \& Young, W. S. (2009). Oxytocin: the great facilitator of life. Progressive Neurobiology, 88(2), 127-151.

10. Ludington-Hoe, S. (2011). Evidence-based review of physiologic effects of kangaroo care. Current Women's Health Reviews, 243-253.

11. Ludington-Hoe, S., Anderson, G., Swinth, S., Thompson, C., \& Hadeed, A. (2004). Randomized controlled trial of kangaroo care: Cardiorespiratory and thermal effects on healthy preterm infants. Neonatal Network, 23, 39-48

12. Marlow, N., Hennessy, E., Bracewell, M., Wolke, D., \& Group, E. S. (2007). Motor and executive function at 6 years of age after extremely preterm birth. Pediatrics, 120, 793-804.

13. Moore, E. R., Anderson, G. C., \& Bergman, N. (2007). Early skin to skin contact for mothers and their healthy newborns. The Cochrane Database of Systematic Reviews, 3.

14. Mori, R., Khanna, R., Pledge, D., \& Nakayama, T. (2010). Meta analysis of physiologic effects of skin to skin contact for newborns and mothers. Pediatrics International, 52, 161-170. http:// dx.doi.org/10.1111/j.1442-200x.2009.02909.x

15. Ross, H. E., \& Young, L. J. (2009). Oxytocin and the neural mechanisms regulating social cognition and afflictive behavior. Frontal Neuroendocrinology, 30(4), 534-547.

16. Vittner, D., Casavant, S., \& McGrath, J. (2015). A meta-ethnography: Skin to skin holding from the caregiver's perspective. Advances in Neonatal Care, 15(3), 191-200.

17. Vittner, D., McGrath, J. M., Robinson, J., Lawhon, g., Cusson, R., Eisenfeld, L., Walsh, S., Young, E., \& Cong, X. (2018). Increases in oxytocin from skin-to-skin contact enhances development of parent-infant relationships. Biological Research for Nursing, 20(1), 54-62. http://doi: $10.1177 / 1099800417735633$

\title{
The Gold Standard for Excellence in Newborn Individualized Developmental Care
}

\author{
What All Newborn Infants and Their Families Deserve
}

\section{Newborn Individualized Developmental Care and Assessment Program (NIDCAP)}

The Newborn Individualized Developmental Care and Assessment Program (NIDCAP), originated in 1984 by Heidelise Als, $\mathrm{PhD}$, is the only comprehensive, family centered, evidence-based approach to newborn developmental care. NIDCAP focuses on adapting the newborn intensive care nursery to the unique neurodevelopmental strengths and goals of each newborn cared for in this medical setting. These adaptations encompass the physical environment and its components, as well as, the care and treatment provided for the infant and his or her family, their life-long nurturers and supporters.

\section{Assessment of Preterm Infants' Behavior (APIB)}

The Assessment of Preterm Infants' Behavior (APIB) (Als et al., 1982) is a comprehensive and systematic research based neurobehavioral approach for the assessment of preterm and fullterm newborns. The APIB provides an invaluable diagnostic resource for the advanced level clinician in support of developmental care provision in a nursery.

\section{NIDCAP Nursery Program}

The NIDCAP Nursery Program provides a comprehensive resource for the self- evaluation by a nursery system of its strengths and goals for integration of NIDCAP principles into all aspects of their functioning. Highly attuned implementation of NIDCAP care for infants and their families, as well as for the staff, in a developmentally supportive environment is a goal as well as a process. External review and validation by the NFI may be sought when a nursery feels it has achieved this distinction. Nurseries that have achieved NIDCAP Nursery certification serve as a model and an inspiration to others. For information on the nursery self-assessment resources as well as the certification process and its eligibility requirements, please see: $w$ ww.nidcap.org; and/or contact Rodd E. Hedlund, MEd, NIDCAP Nursery Program Director at: nidcapnurserydirector@nidcap.org or 785-841-5440. 